\title{
STUDIES ON AUTONOMIC BLOCKADE. II. OBSERVATIONS ON THE NATURE OF BLOOD PRESSURE FALL WITH HIGH SELECTIVE SPINAL ANESTHESIA IN PREGNANT WOMEN ${ }^{1}$
}

\author{
By N. S. ASSALI AND HARRY PRYSTOWSKY 2 \\ (From the Department of Obstetrics, University of Cincinnati College of Medicine, and the \\ Cincinnati General Hospital, Cincinnati)
}

(Submitted for publication March 23, 1950; accepted, July 18, 1950)

In the preceding report (p. 1354 of this issue) it was demonstrated that normal pregnant females at term respond with a striking fall in blood pressure to autonomic blockade with high selective spinal anesthesia or TEAC. With the former, severe side effects, such as nausea, vomiting, cyanosis, fatigue and other symptoms of imminent circulatory collapse, were present while with the latter, these symptoms were absent although the hypotensive levels were the same. This suggested to us the necessity for further investigation on the nature of blood pressure fall with high selective spinal anesthesia in pregnant women.

Among the factors considered of importance in the genesis of spinal hypotension are the following :

(A) Venous stagnation due either to loss of skeletal muscle tone or to blockade of venous tone

(B) Decrease in the cardiac output

(C) Anoxia

(D) Arteriolar dilatation

(E) Bradycardia

In the present study an attempt was made to investigate these various factors.

\section{MATERIAL AND METHOD}

The material consisted of 17 normal pregnant females and four pregnant patients with pre-existing essential hypertension. These patients were selected because they showed a marked fall in blood pressure to both high selective spinal blockade and TEAC. All of them were on the ward and none was in labor when the assays were performed. The age varied from 16 to 41 years, an

1 This investigation was supported (in part) by research grants from The National Heart Institute of The $\mathrm{Na}$ tional Institutes of Health, Public Health Service, and from Parke, Davis and Company, Detroit, Mich.

2 Fellow in Research. Present address: Obstetrical Department, The Johns Hopkins Hospital, Baltimore. average of 26 years. The length of gestation varied from 32 to 40 weeks.

Of the four patients with pre-existing essential hypertension, three were studied in the prepartum and postpartum periods, and one refused the postpartum test.

All of the patients were tested with high selective spinal anesthesia following the method described in the preceding paper. Cold pressor tests were omitted.

\section{RESULTS}

\section{(A) Venous stagnation}

(1) Muscular paralysis. The role of loss of skeletal muscle tone and stagnation of blood in the post arteriolar bed in the genesis of spinal hypotension has been defended by Smith and his associates (1) and others (2-5).

Several investigators (6-10) have opposed this idea. Sarnoff and Arrowood (8) have maintained that similar fall in blood pressure can be obtained in cases submitted to spinal anesthesia with or without muscular paralysis. Milwidsky and de Vries (10) failed in finding any correlation between skeletal muscle tone and blood pressure fall during spinal anesthesia.

The results obtained in this study with high selective spinal anesthesia whereby the motor fibers were unaffected, exclude the possibility of muscular paralysis being a primary factor in spinal hypotension. This assumption is corroborated by the lack of any significant difference in the blood pressure response of toxemic patients who were studied under spinal anesthesia (see preceding report) with and without muscular paralysis.

(2) Blockade of venous tone. Previous works $(11,12)$ have suggested that a certain degree of venous pooling in the lower extremities caused by blockade of venous tone might be a contributing factor in the blood pressure fall of pregnant individuals, following autonomic blockade with 
TEAC. Roman and Adriani (13) and Masters (14) have observed, clinically, rapid ascent of blood pressure levels in patients delivered vaginally or by cesarean section under spinal or caudal anesthesia following emptying the uterus or changing the patient's position. They attributed it to release of a large amount of blood pooled in the lower extremities. Adriani and Roven-

\section{EFFECT OF TEAC \& HIGH SPINAL ANESTHESIA ON ESSENTIAL HYPERTENSION ASSOCIATED WITH PREGNANCY}
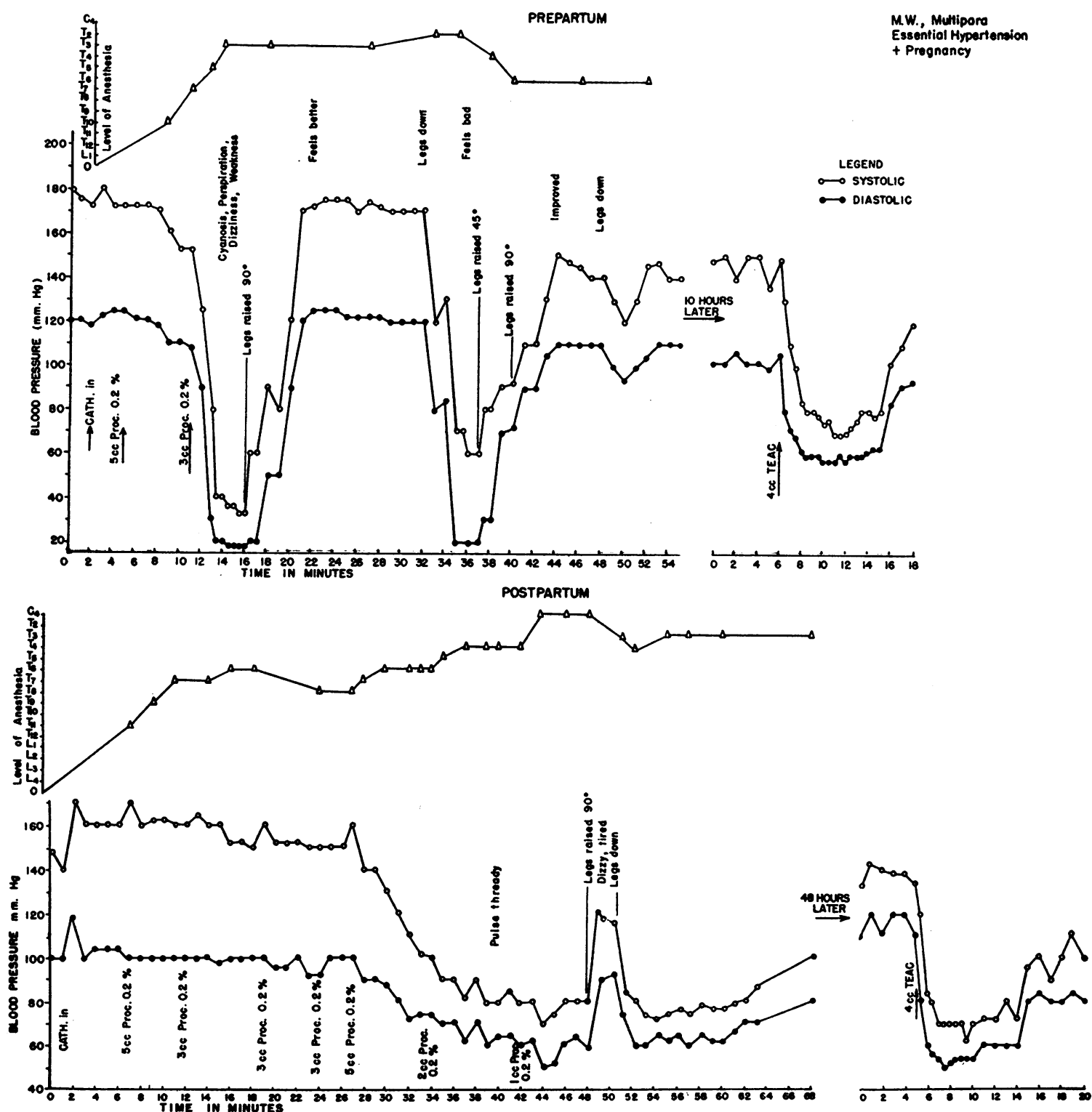

Fig. 1. Effect of Raising the Legs 45 and 90 Degrees on the Blood Pressure of a Pregnant Patient with Pre-Existing Essential Hypertension under High Spinal Blockade in the Prepartum and Postpartum Periods

Note the extreme vasodepressor action of the spinal blockade which brought the blood pressure to shock levels. When the legs were raised, the blood pressure rapidly returned to original levels and the patient's condition improved markedly.

In the postpartum test the effects of the blockade and the pooling were less marked. 
stine (15) have found decreased venous pressure in the arms of patients submitted to high spinal anesthesia, and Doud and Rovenstine (14) have shown increased circulation time under the same condition. They believe these findings corroborate the theory of venous pooling in the lower extremities.

Venous stagnation factor in high selective spinal anesthesia was studied on 12 pregnant subjects in the following manner:

(a) At the height of spinal blockade when the blood pressure had supposedly reached its maximum fall, the patient's legs were raised 90 degrees. This resulted in the return of the blood pressure to its control levels and sometimes higher within one minute. Dramatic changes in the quality and rate of the pulse and disappearance of cyanosis, dizziness, and other shock-like manifestations were instantaneously observed.

Some patients were subjected to different de- grees of leg elevation. Ninety degrees evoked the highest rise in blood pressure (Figure 1).

Turning the patient from the supine to the lateral position also effected a rise in the blood pressure, but it was of much less magnitude than leg elevation.

Raising the lower limbs 90 degrees later became the only method employed to correct spinal hypotension in all the cases studied.

(b) High selective spinal anesthesia was given to three pregnant subjects while the lower extremities were maintained perpendicular to the body. A blood pressure fall of 10 to $15 \mathrm{~mm}$. of $\mathrm{Hg}$ in both systolic and diastolic was observed when the sensory level of anesthesia was between $\mathrm{T}^{2}$ and $\mathrm{C}^{4}$. The patient's general condition was practically unaffected.

When the lower extremities were lowered to the horizontal position, however, the blood pressure fell markedly and severe side effects ensued.

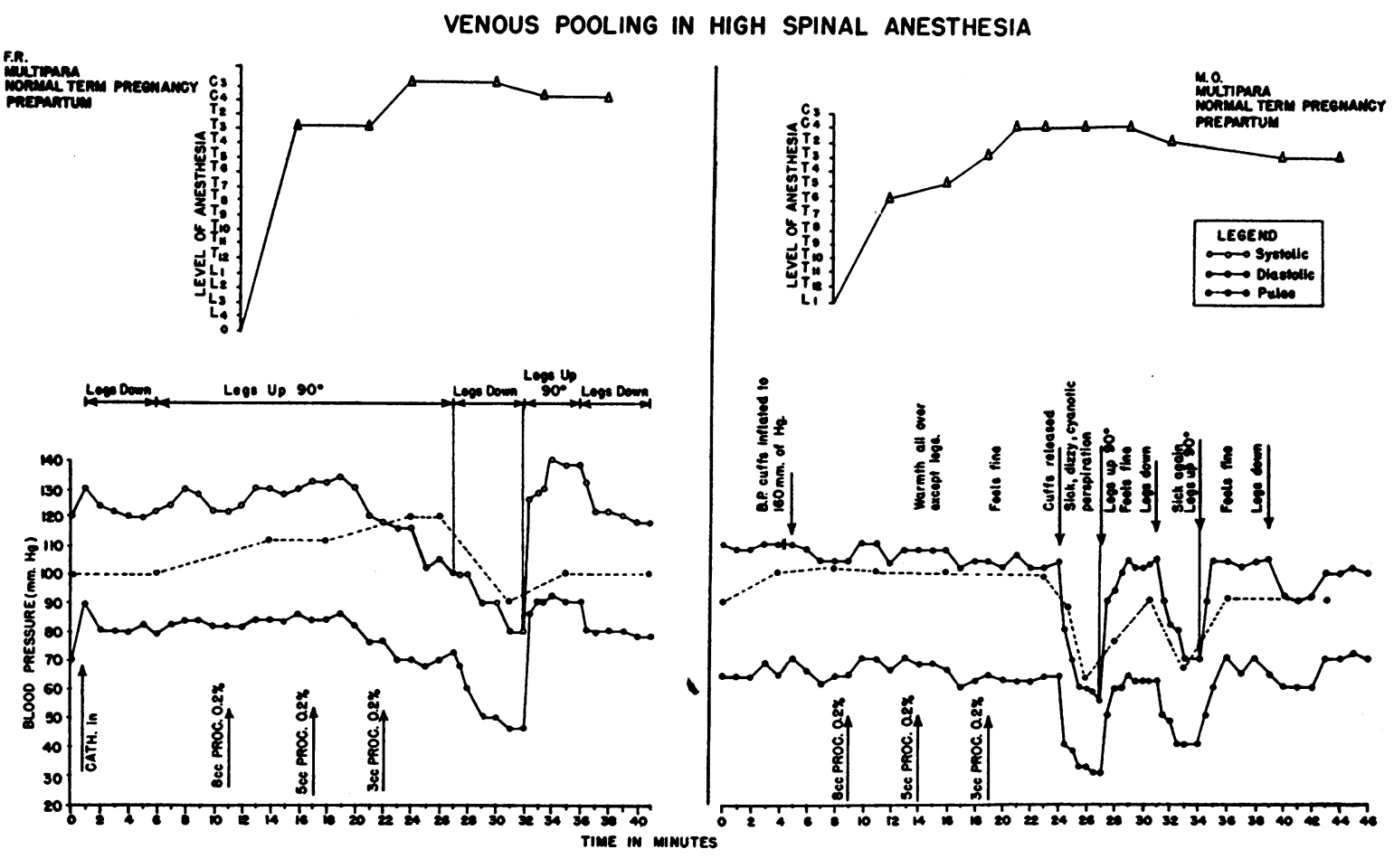

Fig. 2.

(Left) This illustrates the result obtained in a normal pregnant subject given high spinal blockade while the lower extremities were maintained perpendicular to the body. Note the slight fall in blood pressure and rise in pulse rate when the legs were still up, and the marked blood pressure fall and bradycardia when the legs were lowered.

(Right) In this case, the lower extremities were "excluded" by blood pressure cuffs around the thighs. Note the unchanged blood pressure and pulse rate while the cuffs were inflated and the striking blood pressure fall and bradycardia when the cuffs were deflated. The pulse rate followed closely the changes in blood pressure levels. 
These were dispelled immediately and the blood pressure returned to control levels when the legs were re-elevated to the perpendicular position (Figure 2).

(c) Four pregnant subjects were tested with high selective spinal anesthesia while blood pressure cuffs were tightly fixed around the proximal part of the thighs. The legs were first "emptied" of blood by being held elevated and "milked" for 10 minutes. Then, the cuffs were inflated to levels above the systolic pressure $(160 \mathrm{~mm}$. of $\mathrm{Hg}$ ) and the legs lowered to the horizontal position. Procaine solution was given until the sensory anesthesia was at level of $\mathrm{C}^{4}$.

As long as the cuffs were inflated, the patients experienced warmth all over the body except the legs. No side effects were observed. Blood pressure and pulse rate showed no change. When the cuffs were deflated, the blood pressure rapidly fell to shock levels, and bradycardia, cyanosis, nausea, and other severe side effects appeared. The lower extremities became instantaneously congested. Again, when the legs were raised, the blood pressure returned to control levels and the patient experienced striking improvement (Figure 2).

\section{(B) Cardiac output}

The effect of spinal anesthesia on the cardiac output has been a controversial subject. Some investigators $(1-4)$ believe that a diminished cardiac output due to venous stagnation and impairment

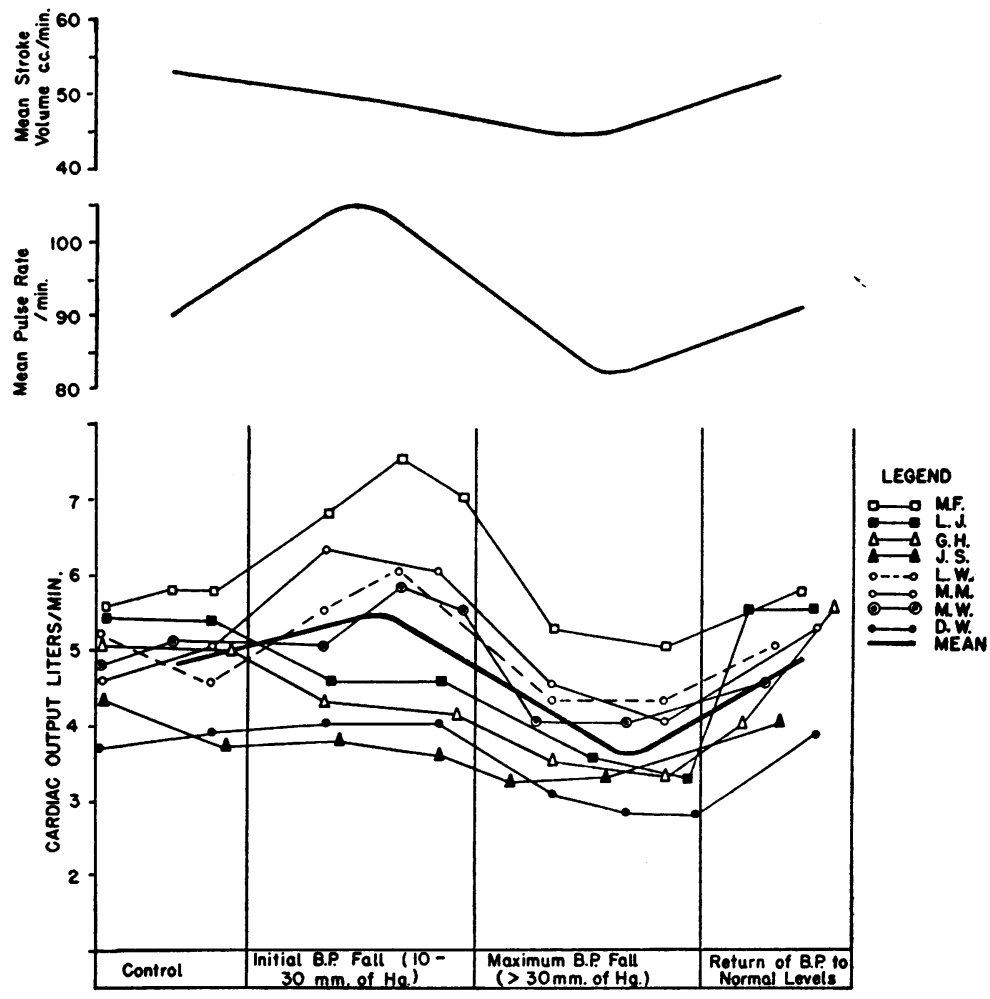

Fig. 3. Cardiac Output, Pulse Rate, and Stroke Volume of Eight Subjects Submitted to High Selective Spinal Anesthesia While They Were lying on a High Frequency Ballistocardiographic Table

In the cardiac output, the heavy line represents the mean figures for the group. The other eight lines represent eight subjects. Each datum in the line represents one ballistocardiographic recording. Note the unchanged or slight rise in cardiac output at the onset of blood pressure fall $(10-30 \mathrm{~mm}$. of $\mathrm{Hg}$ ), and the marked drop at the maximum blood pressure fall. The stroke volume suffered progressive decrease, but returned to normal with the return of blood pressure to control levels. For more details, see text. 
of venous return is the primary cause of spinal hypotension. Others have denied this (16-23.).

The cardiac output was studied in 12 pregnant subjects who received high selective spinal anesthesia while they were lying on a high frequency ballistocardiographic table. The details of this apparatus are described elsewhere (24). Two to three control ballistocardiographic recordings were taken simultaneously with control blood pressure readings; then repeated recordings were made each time the blood pressure fell 10 or more $\mathrm{mm}$. of $\mathrm{Hg}$.

Of the 12 subjects, four were excluded because the ballistocardiographic recordings were disturbed by vomiting.

The results in the remaining eight subjects indicated a mean increase in the cardiac output of 0.7 liter per minute over the control values at the onset of blood pressure fall (fall between 10 and $30 \mathrm{~mm}$. of $\mathrm{Hg}$ ). This increase was caused mainly by a rise in the pulse rate, the stroke volume being approximately the same. However, at the height of blood pressure fall, the cardiac output showed a mean decrease of 1.1 liters per minute from the control value. This decrease was caused by a diminished stroke volume and pulse rate. With the return of the blood pressure to control levels, the cardiac output ascended again to its original values (Figure 3 and Table I).

The statistical analysis of the data on cardiac output is shown in Table II. It is evident that

TABLE I

Data on cardiac output as measured by the ballistocardiograph The initial blood pressure fall was from 10 to $30 \mathrm{~mm}$. of $\mathrm{Hg}$.

\begin{tabular}{l|c|c|c|c}
\hline \hline & \multicolumn{4}{|c}{ Cardiac output } \\
\cline { 2 - 4 } $\begin{array}{c}\text { Patient's } \\
\text { name }\end{array}$ & $\begin{array}{c}\text { Mean C.O. } \\
\text { control }\end{array}$ & $\begin{array}{c}\text { Mean C.O. } \\
\text { at initial } \\
\text { B.P. fall }\end{array}$ & $\begin{array}{c}\text { Mean C.O. } \\
\text { at maximum } \\
\text { B.P. fall }\end{array}$ & $\begin{array}{c}\text { Mean C.O. } \\
\text { at B.P. } \\
\text { return to } \\
\text { normal } \\
\text { levels }\end{array}$ \\
\cline { 2 - 4 } & liters per min. & liters per min. & liters per min. & liters per min. \\
M. F. & 5.7 & 7.1 & 5.1 & 5.7 \\
L. J. & 5.4 & 4.5 & 3.3 & 5.5 \\
G. H. & 5.5 & 4.2 & 3.3 & 4.8 \\
J. S. & 4.0 & 3.4 & 3.2 & 4.0 \\
L. W. & 4.8 & 5.7 & 4.2 & 5.0 \\
M. M. & 4.8 & 6.1 & 4.2 & 5.3 \\
M. W. & 4.9 & 5.4 & 4.0 & 4.5 \\
D. W. & 3.3 & 4.0 & 2.8 & 3.8 \\
\hline Mean for & 4.8 & 5.5 & 3.7 & 4.8 \\
the group & & & & \\
\hline
\end{tabular}

TABLE II

Statistical analysis of the cardiac output*

\begin{tabular}{|c|c|c|}
\hline & T-Score & $\begin{array}{l}\text { Critical } \\
\text { T-Scote }\end{array}$ \\
\hline $\begin{array}{l}\text { (1) Difference between figures of Mean } \\
\text { Control and Mean Maximum Blood } \\
\text { Pressure Fall } \\
\text { Significant }=5 \% \text { level of significance } \\
\text { (2) Difference between figures of Mean } \\
\text { Initial Blood Pressure Fall and Mean } \\
\text { Maximum Blood Pressure Fall } \\
\text { Very Significant = 1\% level of } \\
\text { significance } \\
\text { (3) Difference between figures of Mean } \\
\text { Maximum Blood Pressure Fall and } \\
\text { Mean Return of Blood Pressure to } \\
\text { Normal Levels } \\
\text { Very Significant }=1 \% \text { level of } \\
\text { significance } \\
\text { (4) Difference between figures of Mean } \\
\text { Control Blood Pressure and Mean } \\
\text { Initial Blood Pressure Fall } \\
\text { Not Significant } \\
\text { (5) Difference between figures of Mean } \\
\text { Control Blood Pressure and Mean } \\
\text { Return } \\
\text { Not Significant }\end{array}$ & 0.7 & 3.4 \\
\hline
\end{tabular}

* The statistical analysis was performed by Dr. H. B. Weaver and Mr. O. D. Murphree, Department of Psychology, The University of Cincinnati, using the T-Score Method as outlined in: Lindquist, "Statistical Analysis in Educational Research."

only the values obtained at the maximum fall in blood pressure which showed a definite decrease in cardiac output were statistically significant. This statement is conservative since errors in the output calculations due to change in blood pressure are in the opposite direction; i.e., a drop in blood pressure to shock levels gives output figures that tend to be too high rather than too low (25).

Ballistocardiographic recordings were taken on five patients under the same spinal anesthesia technique in the postpartum periods. In none of them were any blood pressure or cardiac output changes observed.

\section{(C) Anoxia}

Seevers and Waters $(26,27)$ have suggested that anoxia from paralysis of the intercostal muscles and reduced pulmonary ventilation is the main factor in spinal hypotension. Schuberth (16) opposed this theory. Latterell and Lundy (28) failed to find any reduction in oxygen content of the blood under spinal anesthesia.

The role of anoxia was studied on four pregnant subjects who were given high selective spinal anesthesia while they were receiving $100 \%$ oxy- 
gen with tightly fitted anesthesia mask. In all the cases, the blood pressure fell to the same low levels observed in other patients. However, cyanosis and other side effects were practically absent. Slight tachycardia replaced the usual bradycardia. When the oxygen administration was temporarily interrupted, cyanosis, yawning, and nausea rapidly appeared. As soon as the oxygen administration was re-established, the side effects disappeared (Figure 4).

\section{(D) Arteriolar dilatation}

The majority of investigators (6-10, 16-22, 28-30) favor the idea that the fall in the blood pressure with spinal anesthesia is caused by a blockade of the vasoconstrictor fibers and a release of the peripheral resistance.

An attempt was made to calculate the peripheral resistance on some of the pregnant subjects studied under high selective spinal blockade. However, the extreme circulatory collapse observed in most of them, together with the lack of direct blood pressure measurements, made such calculation inconclusive and practically worthless. Nevertheless, judging by the narrowing of the pulse pressure which occurred in most instances, plus the deterioration of the patient's general condition and the decrease in cardiac output, it seems unlikely that a decrease in the peripheral resistance was the main cause of hypotension in high selective spinal anesthesia.

\section{(E) Bradycardia}

A simultaneous slowing of the heart rate and fall in the blood pressure with spinal anesthesia has been unanimously described in the literature. Most investigators $(3,16,29)$ believe that such bradycardia is caused by a blockade of the cardioaccelerator fibers which can be accomplished even with a low concentration of procaine $(8,9)$.

Our observations with high selective spinal anesthesia tend to oppose this concept. Bradycardia was observed to follow closely the fall and rise in blood pressure independently from the anesthetic level. In the cases where no fall in blood pressure occurred, the pulse rate remained the same. Also, in normal pregnant individuals when the legs were "excluded" from the circulation by cuffs or by being held elevated, and the blood pressure did not fall, the pulse rate was
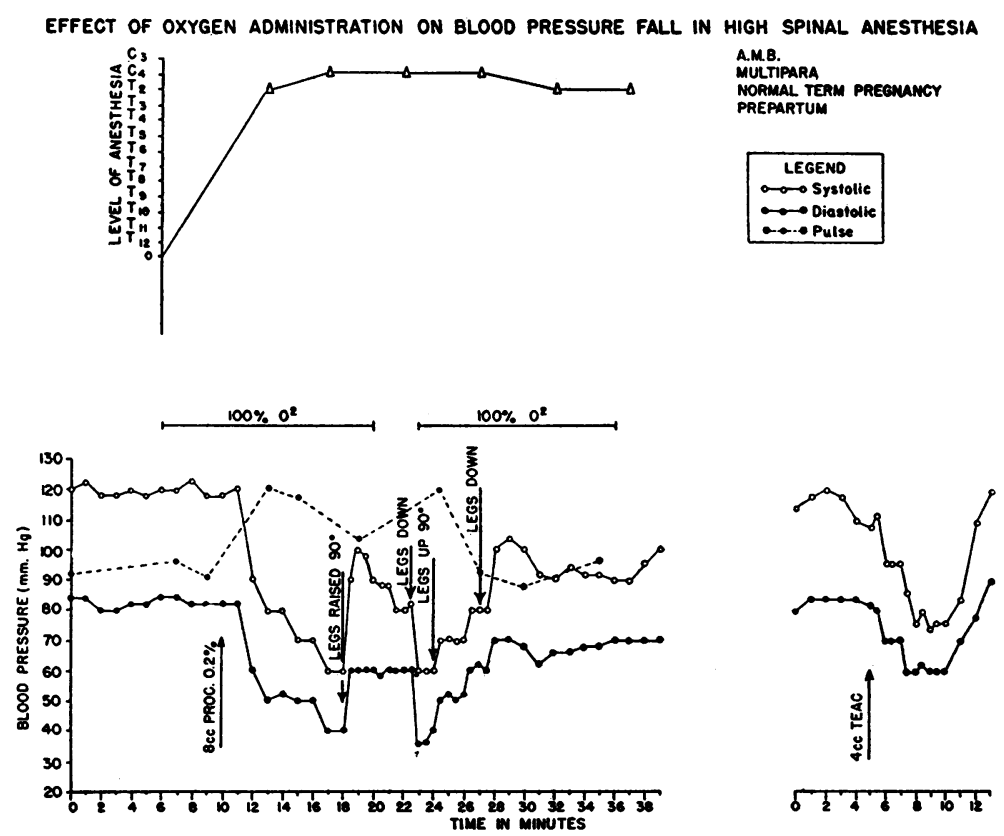

Fig. 4. Normal Pregnant Subject Given O $\mathrm{O}_{2}$ While under High Spinal Anesthesia

There was no relationship between the fall in blood pressure and $\mathrm{O}_{2}$ administration. Side effects were minimal. Tachycardia replaced the usual bradycardia observed in most cases of spinal hypotension. 

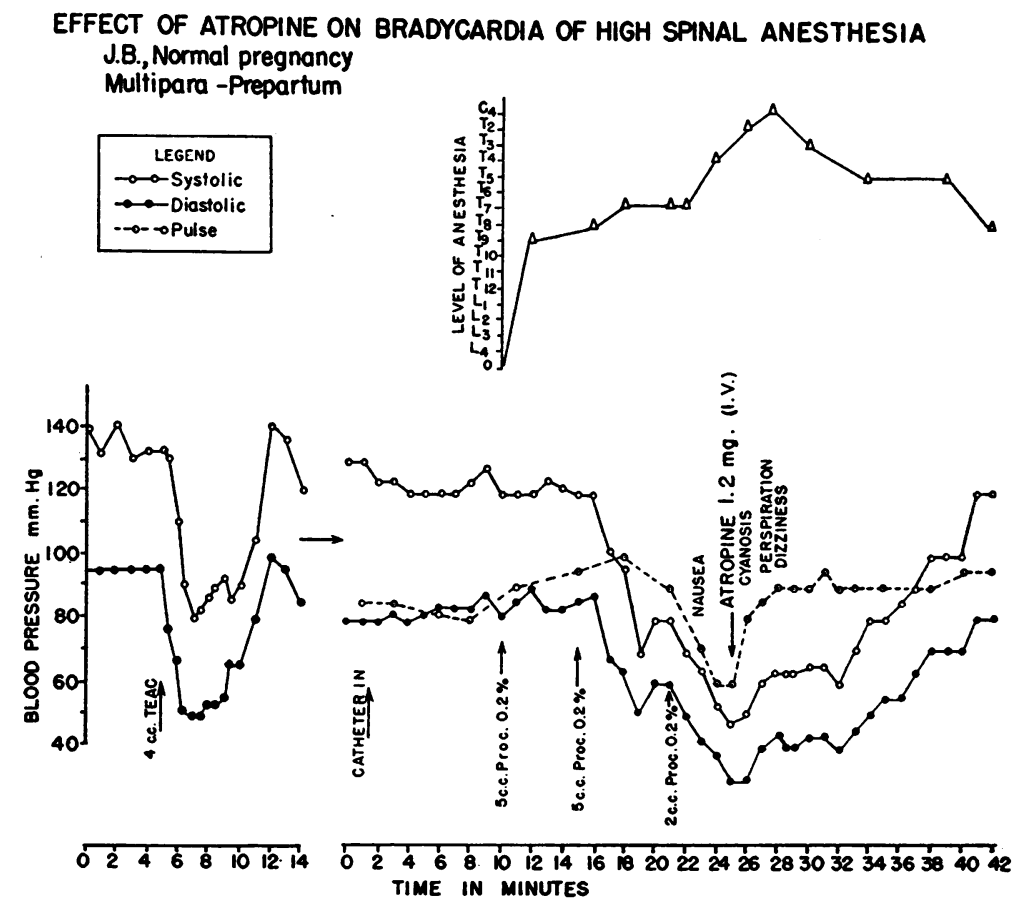

Fig. 5. Normal Pregnant Subject Given 1.2 Mg. of Atropine Sulphate Intravenously at the Height of Spinal Blockade in Order to Determine its EFfect on the Bradycardia

The pulse rate increased slightly after atropine administration, but the blood pressure change was unremarkable. Bradycardia was found to be independent of the anesthetic level.

unchanged (Figure 3). However, it descended invariably at the maximum drop in blood pressure. Atropine given intravenously at the height of bradycardia increased the pulse rate, but did not affect the blood pressure fall (Figure 5). Also when oxygen was administered the bradycardia was not present (Figure 4).

Thus, on the basis of these findings, it seems unlikely that the bradycardia observed with high selective spinal anesthesia is caused by blockade of the cardioaccelerator fibers. It appears rather to be related to the severity of hypotension and possibly to vagal stimulation and anoxia, since it was abolished by atropine and oxygen.

Similar bradycardia in the presence of marked hypotension has been described in cases with orthostatic hypotension $(31,32)$. Also, in this syndrome, the pulse rates parallel closely the changes in blood pressure levels.

\section{DISCUSSION}

Satisfactory explanation for the mechanism of fall in the blood pressure under spinal anesthesia is still lacking. That autonomic blockade of the vasoconstrictor fibers can be accomplished with intrathecal administration of procaine is commonly accepted. However, the result of such blockade on the blood pressure in health and disease depends on the extent of autonomic vasoconstrictor fibers blocked (33), and on the degree of pre-blockade neurogenic vasoconstrictor tone present.

The fact that only normal pregnant patients in the prepartum and patients with pre-existing essential hypertension responded with a marked fall in blood pressure to autonomic blockade with high selective spinal anesthesia indicates the presence of an increased neurogenic tone in these conditions.

The present data show, however, that the blood pressure fall with high selective spinal anesthesia in pregnant females is related to venous stagnation in the lower extremities, because the "exclusion" of the circulation to the legs from the general circulation by cuffs or by 90 degree elevation prevented spinal hypotension. It is also evident 
that the venous stagnation is not related to loss of skeletal muscle tone, nor to anoxia. Two hypotheses could be postulated to explain the mechanism by which such venous stagnation may lead to spinal hypotension:

(1) The blood pressure of normal pregnant women at term is maintained by increased neurogenic tone possibly to both arterioles and veins. Whether this increased tone is more accentuated in certain areas of the body cannot be stated from this study. Such neurogenic tone possibly serves to compensate for the increased tendency to venous pooling in the lower extremities caused by the heavy uterus lying on the major vessels and by the increased intra-abdominal pressure. When this tone is blocked by high selective spinal anesthesia, both arteriolar and venous systems collapse; the latter more than the former, possibly because the veins lack sufficient intrinsic tone. This vascular collapse results in increased vascular capacity of the legs. Stagnation of blood in the lower extremities occurs in quantity sufficient to impair the venous return to the heart, decrease the cardiac output and drop the blood pressure to shock levels. This does not happen, to such extent, in toxemic pregnancy, possibly because the arteriolar and venous tones are maintained by different mechanisms.

(2) The second hypothesis is that spinal hypotension could be caused by blockade of the compensatory homeostatic vasoconstrictor reflexes in different areas of the body; the pooling of blood in the legs, even in moderate amounts, serves only to precipitate the blood pressure fall, as has been shown by Freis and his co-workers (34). Under such circumstances, the "exclusion" of the legs from the general circulation serves merely to restore that small amount of blood to the systemic circulation, thereby reestablishing the circulatory adjustments. Although this hypothesis is of considerable interest, the extent to which it contributes to the explanation of spinal hypotension in pregnancy still remains to be determined.

Evidently, measurements of limb volume and "effective" circulating blood volume would be of great help in elucidating both hypotheses. Nevertheless, the works of Asmussen and his co-workers (35) and of Landis and Hortenstine (36) lead to the belief that blood can be pooled in the lower extremities in quantity sufficient to cause signifi- cant hypotension, even in the presence of intact compensatory vasoconstrictor reflexes.

The bradycardia which follows high selective spinal anesthesia could be explained on the basis of venous stagnation in the lower extremities with impairment of venous return to the heart (Bainbridge reflex). However, its disappearance with atropine and oxygen makes it more likely to be related to vagal stimulation and anoxia. Further studies to elucidate the mechanism of such vagal stimulation and its relation to anoxia are needed.

\section{SUMMARY AND CONCLUSION}

1. A study on the nature of fall in blood pressure with high selective spinal anesthesia was performed on 17 normal pregnant subjects and four patients with pre-existing essential hypertension associated with pregnancy.

2. The fall in blood pressure was found not to be related to loss of skeletal muscle tone or to anoxia.

3. A statistically significant decrease in the cardiac output was encountered at the maximum fall in blood pressure.

4. Spinal hypotension was found to be related to venous stagnation in the lower extremities. It could be prevented by "exclusion" of the legs from the systemic circulation by cuffs or by 90 degree elevation.

5. The possible mechanisms by which such venous stagnation might produce hypotension were discussed.

6 Bradycardia was not related to the blockade of cardioaccelerator fibers. It seemed to be related to the degree of hypotension and possibly to vagal stimulation and anoxia.

\section{ACKNOWLEDGMENTS}

The authors are indebted to Drs. John Braunstein, J. Kaufman, and R. Helms and Mrs. G. Herwitz for the ballistocardiographic recordings.

\section{BIBLIOGRAPHY}

1. Smith, H. W., Rovenstine, E. A., Goldring, W., Chasis, H., and Ranges, H. A., The effects of spinal anesthesia on the circulation in normal unoperated man with reference to the autonomy of the arterioles and especially those of the renal circulation. J. Clin. Invest., 1939, 18, 319.

2. Papper, E. M., Bradley, S. E., and Rovenstine, E. A., 
Circulatory adjustments during high spinal anesthesia. J. A. M. A., 1943, 121, 27.

3. Rovenstine, E. A., Papper, E. M., and Bradley, S. E., Circulatory adjustments during spinal anesthesia in normal man with special reference to the autonomy of arteriolar tone. Anesthesiology, 1942, 3, 421.

4. Doud, E. A., and Rovenstine, E. A., Changes in the velocity of the blood flow during spinal anesthesia. Anesthesiology, 1940, 1, 82.

5. Henderson, Y., Tonus and the venopressor mechanism; the clinical physiology of a major mode of death. Medicine, 1943, 22, 223.

6. Koster, H., Blood pressure changes during spinal anesthesia in non-operative cases. Arch. Surg., 1942, 45, 596.

7. Gregory, R., and Levin, W. C., Studies on hypertension. VII. Mechanism of the fall in arterial pressure produced by high spinal anesthesia in patients with essential hypertension. Arch. Int. Med., 1948, 81, 352.

8. Sarnoff, S. J., and Arrowood, J. G., Differential spinal block: a preliminary report. Surgery, 1946, $20,150$.

9. Sarnoff, S. J., and Arrowood, J. G., Differential spinal block. II. The reaction of sudomotor and vasomotor fibers. J. Clin. Invest., 1947, 26, 203.

10. Milwidsky, H., and de Vries, A., Regulation of blood pressure during spinal anesthesia: observations on intramuscular pressure and skin temperature. Anesthesiology, 1948, 9, 258.

11. Brust, A. A., Assali, N. S., and Ferris, E. B., Evaluation of neurogenic and humoral factors in blood pressure maintenance in normal and toxemic pregnancy using tetraethylammonium chloride. J. Clin. Invest., 1948, 27, 717.

12. Assali, N. S., Brust, A. A., Garber, S. T., and Ferris, E. B., Comparative study of the effects of tetraethylammonium chloride and veratrum viride on blood pressure in normal and toxemic pregnancy. J. Clin. Invest., 1950, 29, 290.

13. Roman, D. A., and Adriani, J., Spinal anesthesia for cesarean section. New Orleans Med. \& Surg. J., 1948, 101, 19.

14. Masters, W. H., Continuous caudal analgesia; a report of 1500 consecutive cases. Am. J. Obst. \& Gynec., 1948, 56, 756.

15. Adriani, J., and Rovenstine, E. A., Effects of spinal anesthesia upon venous pressure in man. Proc. Soc. Exper. Biol. \& Med., 1940, 45, 415.

16. Schuberth, O. O., On the disturbance of the circulation in spinal anesthesia; an experimental study. Acta chir. Scandinav., 1936, Supp. 43.

17. Burch, J. C., and Harrison, T. R., The effect of spinal anesthesia on cardiac output. Arch. Surg., 1930, 21, 330.

18. Burch, J. C., and Harrison, T. R., The effect of spinal anesthesia on arteriolar tone. Arch. Surg., 1931, 22, 1040.
19. Harrison, T. R., Failure of The Circulation. Baillière, Tindall \& Cox, London, 1939, 2nd Ed.

20. Blalock, A., Acute circulatory failure as exemplified by shock and hemorrhage. Surg., Gynec. \& Obst., 1934, 58, 551.

21. Goldfarb, W., Provisor, B., and Koster, H., Circulation during spinal anesthesia. Arch. Surg., 1939, 39, 429.

22. Sobin, S. S., The role of the sympathetic nervous system in human arterial hypertension. Cardiac output studies in differential spinal block. Proc. West. Soc. for Clin. Research, in Am. J. Med., 1949, 6, 386.

23. May, L. G., Bennett, A., Lane, A. L., Futch, E. D., Lynn-Schoomer, M., and Gregory, R., Effect of high spinal anesthesia on the cardiac output of normal and hypertensive patients. Proc. South. Soc. Clin. Research, in Am. J. Med., 1949, 7, 251.

24. Braunstein, J. R., Oelker, C. F., and Gowdy, R. C., Design of a two dimensional ballistocardiograph. J. Clin. Invest., 1950, 29, 1219.

25. Cournand, A., Riley, R. L., Bradley, S. E., Breed, E. S., Noble, R. P., Lawson, H. D., Gregersen, M. I., and Richards, D. W., Studies of the circulation in clinical shock. Surgery, 1943, 13, 964.

26. Seevers, M. H., and Waters, R. M., Circulatory changes during spinal anesthesia. California \& West. Med., 1931, 35, 169.

27. Seevers, M. H., and Waters, R. M., Respiratory and circulatory changes during spinal anesthesia. J. A. M. A., 1932, 99, 961.

28. Latterell, K. E., and Lundy, J. S., Oxygen and $\mathrm{CO}_{2}$ content of arterial blood before and during spinal analgesia. Anesthesiology, 1949, 10, 677.

29. Ferguson, L. K., and North, J. P., Observations on experimental spinal anesthesia. Surg., Gynec., \& Obst., 1932, 54, 621.

30. Bradshaw, H. H., The fall in blood pressure during spinal anesthesia. Ann. Surg., 1936, 104, 41.

31. Eichna, L. W., Horvath, S. M., and Bean, W. B., Post-exertional orthostatic hypotension. Am. J. M. Sc., 1947, 213, 641.

32. Stead, E. A., Jr., and Ebert, R. V., Postural hypotension: a disease of the sympathetic nervous system. Arch. Int. Med., 1941, 67, 546.

33. Neumann, C., Foster, A. D., Jr., and Rovenstine, E. A., The importance of compensating vasoconstriction in unanesthetized areas in the maintenance of blood pressure during spinal anesthesia. J. Clin. Invest., 1945, 24, 345.

34. Freis, E. D., Stanton, J. R., Finnerty, F. A., Jr., Rath, C. E., Jr., and Wilkins, R. W., The phenomenon of "congestion collapse"; its pathogenesis and significance. J. Clin. Invest., 1950, 29, 813.

35. Asmussen, E., Christensen, E. H., and Nielsen, M., The regulation of circulation in different postures. Surgery, 1940, 8, 604.

36. Landis, E. M., and Hortenstine, J. C., Functional significance of venous blood pressure. Physiol. Rev., 1950, 30, 1. 